\title{
Staphylococcus aureus photodynamic inactivation mechanisms by rose bengal: use of antioxidants and spectroscopic study
}

\author{
S. Sabbahi ${ }^{1} \cdot$ L. Ben Ayed ${ }^{2} \cdot$ M. Jemli ${ }^{3}$
}

Received: 11 June 2016 / Accepted: 26 March 2018 / Published online: 4 April 2018

(c) The Author(s) 2018

\begin{abstract}
This study aims to follow the photodynamic and spectroscopic properties of dianionic rose Bengal disodium salt (RB) on Staphylococus aureus (S. aureus) in phosphate buffer solution (PBS) at pH 7.3. It focused on: (1) the effect of several reactive oxygen species (ROS) antioxidants used [such as sodium azide $\left(\mathrm{NaN}_{3}\right)$, L-tryptophan (L-Trp) and D-mannitol] on the RB photodynamic efficiency as a mean to identify the main ROS attributed, and (2) the possible interactions of the RB with the important singlet oxygen quencher used namely tryptophan and/or between the dye and the bacteria $S$. aureus thanks to a spectroscopic study. The results showed that $20 \mu \mathrm{M}$ of $\mathrm{RB}$ and $10 \mathrm{~min}$ of visible light $\left(50 \mathrm{~mW} / \mathrm{cm}^{2}\right)$ with a light fluence dose of $30 \mathrm{~J} / \mathrm{cm}^{2}$ are crucial for a good photodynamic action, achieving a reduction of $79.4 \%$ in the viability. Rose Bengal photodynamic action was in part inhibited by D-mannitol and L-Trp, indicating the mediation by. $\mathrm{OH}$ and ${ }^{1} \mathrm{O}_{2}$, respectively. The high inhibition of the RB activity against $S$. aureus by L-Trp is not due only to its singlet oxygen quencher ability but it is mainly due to the interaction between RB and L-Trp as shown spectrophotometrically.
\end{abstract}

Keywords Absorption spectra $\cdot$ Quenchers $\cdot$ Tryptophan $\cdot$ Sodium azide $\cdot$ Mannitol $\cdot$ Visible light

\section{Introduction}

Light induces excitation of the photosensitizer (PS) molecules to the singlet excited state which can be converted into the triplet excited compound. This triplet state may react with surrounding molecules in two types of photooxidative reaction. Type I involves electron or hydrogen atom transfer, producing radical forms of the substrate which may react with oxygen to form peroxides, superoxide ions, and hydroxyl radicals. The Type II mechanism involves energy transfer between the excited triplet state of the PS and the

S. Sabbahi

sabbahisonia@yahoo.fr

1 Laboratoire de Microbiologie des Eaux Usées et des Boues Résiduaires, Institut National de Recherche en Génie Rural Eaux et Forêts, Rue Hédi Karray, B.P. 10, 2080 Ariana, Tunis, Tunisie

2 Laboratoire Sciences et Techniques de l'Eau, Département du Génie Rural, Eaux et Forêts, Institut National Agronomique de Tunisie, 43 Avenue Charles Nicolle, 1082 Tunis, Tunisie

3 Laboratoire des Bioprocédés Environnementaux, Pôle d'Excellence Régional (PER, AUF), Centre de Biotechnologie de Sfax, Université de Sfax, Route de Sidi Mansour Km 6, PO Box 1177, 3018 Sfax, Tunisie ground state of molecular oxygen, generating singlet oxygen $\left({ }^{1} \mathrm{O}_{2}\right)$, the first excited state of oxygen. Both mechanisms may occur simultaneously (Taniellian et al. 2000; Calin and Parasca 2009) and generate a variety of oxygen species, which can lead to cell apoptosis (Moan and Peng 2003). In fact, singlet oxygen, due to its high electrophilicity, is capable of oxidizing phenols, sulphides and amines (DeRosa and Crutchley 2002) possibly through a charge transfer intermediate (Gollnick 1978) and can interact with numerous enzymes, leading to the inhibition of protein synthesis and to the molecular alteration of DNA strands, which alters the transcription of the genetic material during its replication and in this way, leading to microbial death (Calin and Parasca 2009; Agnez-Lima et al. 2012). Like nucleic acids and proteins, unsaturated lipids are also prominent targets of ${ }^{1} \mathrm{O}_{2}$ and free radical attack. The hydroxyl radical is identified as initiating lipid peroxidation by abstracting hydrogen atoms from fatty-acid side chains (Shevchuk et al. 2002). Among xanthenes dyes which are potent photosensitizers (PSs) generating reactive oxygen species such as singlet oxygen (Kato et al. 2012), RB is one of the most efficient and widely used sources of ${ }^{1} \mathrm{O}_{2}(80 \%)$ in polar solvents such as water (Neckers 1989; Alarcón et al. 2009), with a high quantum yield of 0.75-0.76 (Gandin et al. 1983; Redmon and Gamlin 1999). 
The RB, is a cyclic compound that contains three aromatic rings in a linear arrangement and an oxygen atom in the centre of the ring, which absorbs light in the visible spectrum (Costa et al. 2010), exhibiting intense absorption bands in the green area of the visible spectrum $(480-550 \mathrm{~nm})($ DeRosa and Crutchley 2002) with maximum absorption around $549 \mathrm{~nm}$ in diluted aqueous solutions (Xu and Neckers 1987). Therefore, according to these properties, we investigated in this current study the mechanisms of photodynamic action of this PS, against a Gram-positive bacterium (S. aureus), used as a pathogenic microorganism model.

The simplest approach for determining whether ${ }^{1} \mathrm{O}_{2}$ and/ or free radicals are involved in a photodynamic inactivation process is to study the PS efficiency in the presence of various quenchers and free radicals scavengers (Nitzan et al. 1989; Tavares et al. 2011). Singlet oxygen reacts primarily with five amino acids, which are tryptophan, histidine, tyrosine, methionine and cysteine to form peroxides (Michaeli and Feitelson 1995 and Michaeli and Feitelson 1997) and in high yields especially for tryptophan, tyrosine and histidine residues, both free and on proteins (Gracanin et al. 2009).

In previous studies (Jemli et al. 2002; Sabbahi et al. 2008a, 2013), RB has been exploited, at laboratory scale, as a promising PS in wastewater treatment against faecal bacteria indicators, pathogenic bacteria and helminth ova destruction. But the inactivation mechanisms by this PS have not been yet well elucidated. Consequently, it is quite difficult to predict the PS photo disinfection behaviour against any microorganism such as bacteria. By the way, in this study, the ultimate objective was to identify the main mechanisms action involved in S. aureus strain photoinactivation by dianionic rose bengal PS, which could effectively be carried out in buffer (PBS). In this context, three antioxidants including two singlet oxygen quenchers (sodium azide and L-tryptophan) and one free radical scavenger (D-mannitol) were used to search the main oxygen species causing damage to bacteria by the photoactivated RB, to design improved PS and to elucidate the best conditions for $S$. aureus photoinactivation. In addition, it is of interest to define the relationship between the spectroscopic, photophysical and photochemical properties of this PS and its photosensitization effect and damage mechanisms for the selected microbial strain.

\section{Materials and methods}

\section{Chemicals}

Rose bengal, 2,4,5,7-tetraiodo-3', 4', 5', 6' tetrachlorofluoresein disodium salt used is from Prolabo (Fontenay-Sous-Bois, France). The chemical structure (Fig. 1) was used as received, as photosensitizer. The dye was added to the buffer solution ( $\mathrm{pH}$ 7.3) for photodynamic

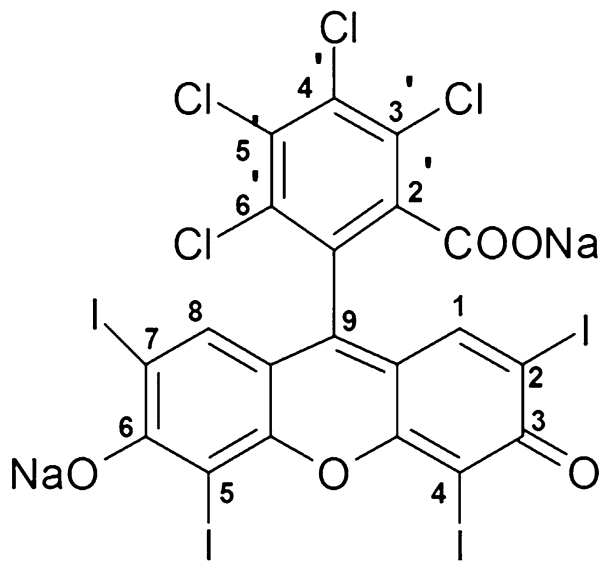

Fig. 1 Chemical structure of rose bengal (RB)

experiments of concentration equal to $20 \mu \mathrm{M}$ for $S$. aureus. D-mannitol, L-tryptophan (RPE Analyticals Farmitalia Carlo Erba, Milano, Italy) and sodium azide (Sigma-Aldrich, Germany) were used as antioxidants.

\section{Illuminations experiments}

All illumination experiments were carried out with a $500 \mathrm{~W}$ halogen lamp light source (OSRAM, Italy) which emits in the range of 500-750 nm with a peak at $650 \mathrm{~nm}$, as previously described in Sabbahi et al. (2008b). To avoid heating of the samples, the photocontainers (with a final volume of $2.5 \mathrm{~mL}$ ) were run at $28{ }^{\circ} \mathrm{C}$ covered by ice to maintain the temperature constant. The irradiance at the level of microorganism sample was $50 \mathrm{~mW} / \mathrm{cm}^{2}$ as measured with solarmeter-pyranometer (Instruments HEANNS messger.A.T.E. Solar 118).

\section{Bacterial strain and growth conditions}

The selection of $S$. aureus as bacterium model tested here is based first, on its pathogenicity (Oliveira et al. 2014) and second, on its frequency in wastewater samples and resistance to conventional disinfection treatments (Thompson et al. 2013).

Staphylococcus aureus strain ATCC 25923 isolated derive from surgical samples collected from the microbiological department of the Children's hospital in Tunis, Tunisia. Staphylococcus aureus strain was grown aerobically overnight at $37^{\circ} \mathrm{C}$ for $18 \mathrm{~h}$ in liquid culture (nutrient broth, $1 \%$ tryptone, $0.5 \%$ yeast extract, $0.5 \% \mathrm{NaCl} \mathrm{w} / \mathrm{v}$ ) from BioRad (Marnes-La-Coquette, France). The culture was pelleted by centrifugation $\left(10 \mathrm{~min}\right.$ at $\left.4{ }^{\circ} \mathrm{C}, 1050 \times g\right)$, the supernatant discarded and the cells were washed twice with phosphatebuffered saline (PBS, $2.7 \mathrm{mM} \mathrm{KCl}, 137 \mathrm{mM} \mathrm{NaCl}, \mathrm{pH} 7.3$ ) (Lab Online, France) and resuspended in a total volume of 
$2.5 \mathrm{~mL}$ PBS to an optical density of 0.4 at $660 \mathrm{~nm}$, corresponding to approximately $5 \times 10^{7}$ colony-forming units per $\mathrm{mL}$ (CFUs/mL). This absorbance was measured using a Spectronic ${ }^{\circledR} 20$ Genesys $^{\mathrm{TM}}$ spectrophotometer (Thermo Electron Corporation, France).

\section{Experimental setup: in vitro photodynamic inactivation}

Cells precultured in nutrient broth were washed twice with phosphate-buffered saline (PBS, pH 7.3 containing $2.7 \mathrm{mM}$ $\mathrm{KCl}$ and $137 \mathrm{mM} \mathrm{NaCl}$ ). The cells were diluted in PBS to a final density of $5.1 \times 10^{7}$ cells per mL, corresponding to an absorbance of 0.4 at $660 \mathrm{~nm}$. This bacterial suspension was equally distributed into a 96 -well-flat-bottomed microliter plate (Sterilin, Stafford, UK) and incubated for 10 min with $100 \mu \mathrm{L}$ of PS which were added to achieve final concentration of $20 \mu \mathrm{M}$ corresponding to a total volume of $2.5 \mathrm{~mL}$ per beaker. The samples were protected from light and were incubated for $10 \mathrm{~min}$ in the dark, at $25-30{ }^{\circ} \mathrm{C}$ with RB $(20 \mu \mathrm{M})$, as used for the PDI experiment. Control treatments were as follows: (1) without PS but illuminated; (2) with PS, but no light and (3) only suspension (no PS, no light). In the dark control, the PS at concentration used $(20 \mu \mathrm{M})$ was added to the beaker and they were covered with aluminum foil.

After irradiation, $0.1 \mathrm{~mL}$ samples were taken off and serially diluted (tenfold) with PBS. Aliquots $(0.1 \mathrm{~mL})$ were spread over selective culture medium: Chapman-Mannitol Salt Agar (Bio-Rad, Diagnostic Pasteur, Marnes-LaCoquette, France); the number of colony-forming units per milliliter (CFUs/mL) on each plate was then counted following $36 \mathrm{~h}$ of incubation at $37{ }^{\circ} \mathrm{C}$ and likewise, plated on nutrient agar (Bio-Rad, Diagnostic Pasteur, Marnes-LaCoquette, France) after incubation at the same temperature for 24-48 $\mathrm{h}$. The survival fraction (CFU per $\mathrm{mL}$ ), is given by the equation $N_{\mathrm{i}} / N_{0}$ as previously described by Sabbahi et al. (2008b). Each experiment was carried out three times.

\section{Spectrophotometric study}

Spectrophotometric study was carried out with a Spectronic ${ }^{\circledR} 20$ Genesys $^{\mathrm{TM}}$ spectrophotometer (Thermo Electron Corporation, France). Samples for spectrophotometric measurements were prepared by dilutions of RB stock solution to the desired concentration $(20 \mu \mathrm{M})$. Shortly before the measurements were taken, the appropriate fresh bacterial suspension was added to RB solution. The absorption spectra of the dye were obtained in the visible region ranging from 400 to $700 \mathrm{~nm}$ where the monomer and dimer absorption band of this dye were distinct.

\section{Statistics}

All experiments were performed in triplicate. Survival values are expressed as means \pm standard deviation. The differences among treatments were compared by analysis of variance using one-way ANOVA test, performed with the statistical package for Social Science 20.0 for windows (SPSS IBN Corp., 2011) software and the Duncan test: $p$ value $<0.05$ was considered to be statistically significant.

\section{Results and discussion}

This section will include two components: (1) the evaluation of the RB photodynamic effect against $S$. aureus bacterium and its mechanisms involved by quenching the main ROS produced and (2) the spectrophotometric study to reveal the possible interactions between the tryptophan and the dye and/or the dye and the bacterium.

\section{Effect of RB photosensitization on S. aureus inactivation}

The RB sensitization procedure on $S$. aureus inactivation was performed in phosphate buffer instead of the culture medium because this latter is providing additional protection as the antioxidants themselves. Samples with RB were kept in the dark (dark control) for 10 and 30 min and illuminated samples without RB (light control) served as controls. After 10 min of dark incubation, RB did not induce a significant death neither in the presence nor in the absence of antioxidants (ANOVA, $p>0.05$ ). Thus, RB showed dark toxicity of only $0.1 \mathrm{CFU} \log$ reduction after $10 \mathrm{~min}$ exposure showing cell survival of about $76.5 \pm 1.4 \%$. After $30 \mathrm{~min}$, RB showed a much higher level of dark killing of $S$. aureus bacteria (0.25 CFU log reduction; $54.9 \pm 1.0 \%$ survivals) than it did after 10 min $(76.5 \pm 1.4 \%$ survival) (ANOVA, $p<0.05$ ) (Table 1). Therefore, the cytotoxic effect of RB and the bacteria inactivation were increased by rising dark incubation time (Table 1).

By the way, the dark toxicity of RB is somewhat unclear, as the dye has been described by certain groups as cytotoxic (Paulino et al. 2005; Shrestha et al. 2012) and by other groups as noncytotoxic (Chilvers et al. 1999), depending on the PS concentrations tested, the microorganisms studied and their initial cell concentration, the dark incubation time, etc. In fact, according to Kato et al. (2012), the photoinactivation of the membrane functions of $S$. aureus induced by xanthenes dyes such as rose bengal, phloxine $\mathrm{B}$, erythrosine $\mathrm{B}$ and eosin B showed that when these specific dyes were applied with $1 \mu \mathrm{M}$ in the dark, none of them had an effect.

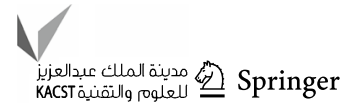


Table 1 Photoinactivation of $S$. aureus cultures in PBS ( $\mathrm{pH} 7.3$ ) in the dark with RB $(20 \mu \mathrm{M})$ after 10 and $30 \mathrm{~min}$ in the presence of three antioxidants $(10 \mathrm{mM}): \mathrm{NaN}_{3}$, Trp and mannitol

\begin{tabular}{|c|c|c|c|}
\hline \multirow[t]{2}{*}{ Medium } & \multicolumn{3}{|c|}{ Viability after $10 \mathrm{~min}$ of phototreatment } \\
\hline & $\overline{\mathrm{CFU} \mathrm{m}} \mathrm{m}^{-1}$ & Survival fraction $(\%)$ & $\begin{array}{l}\text { Inactivated } \\
\text { bacteria (\%) }\end{array}$ \\
\hline Without RB & $4.9 \times 10^{7}$ & $96.1 \pm 2.0$ & $3.9 \pm 2.0$ \\
\hline RB alone & $3.9 \times 10^{7}$ & $76.5 \pm 1.4$ & $23.5 \pm 1.4$ \\
\hline $\mathrm{RB}+\mathrm{N}_{3}^{-\mathrm{a}}$ & $3.9 \times 10^{7}$ & $76.5 \pm 1.0$ & $23.5 \pm 1.0$ \\
\hline $\mathrm{RB}+\operatorname{Tr}^{\mathrm{b}}$ & $3.1 \times 10^{7}$ & $60.8 \pm 0.5$ & $39.2 \pm 0.5$ \\
\hline $\mathrm{RB}+$ mannitol & $4.5 \times 10^{7}$ & $88.2 \pm 1.3$ & $11.8 \pm 1.3$ \\
\hline \multicolumn{4}{|c|}{ Viability after $30 \mathrm{~min}$ of phototreatment } \\
\hline Without RB & $4.8 \times 10^{7}$ & $94.1 \pm 1.9$ & $5.9 \pm 1.9$ \\
\hline RB alone & $2.8 \times 10^{7}$ & $54.9 \pm 1.0$ & $45.1 \pm 1.0$ \\
\hline $\mathrm{RB}+\mathrm{N}_{3}^{-}$ & $2.6 \times 10^{7}$ & $51.0 \pm 0.6$ & $49.0 \pm 0.6$ \\
\hline $\mathrm{RB}+\operatorname{Trp}$ & $2.6 \times 10^{7}$ & $51.0 \pm 0.5$ & $49.0 \pm 0.5$ \\
\hline $\mathrm{RB}+$ mannitol & $4.2 \times 10^{7}$ & $82.3 \pm 14.1$ & $17.6 \pm 14.1$ \\
\hline
\end{tabular}

S. aureus Staphylococcus aureus, $P B S$ phosphate buffer solution, $R B$ rose bengal, $\mathrm{NaN}_{3}$ sodium azide

${ }^{\mathrm{a}} N_{3}^{-}$anion azide reactive, ${ }^{\mathrm{b}} \operatorname{Tr} p$ tryptophan

By Paulino et al. (2005), when Streptococcus mutans was treated with different concentrations $(0-10 \mu \mathrm{M})$ of $\mathrm{RB}$, it was observed that in the dark, this dye was toxic only to the cells tested at concentrations above 5.0 $\mu \mathrm{M}$. Indeed, the results presented here confirmed a dark incubation timedependent increase in the death rate of $S$. aureus with RB for $30 \mathrm{~min}$.

Under the same conditions and in a previous work, the effect caused only by the light with or without antioxidants used (light control) on S. aureus, showed that after 10 and $30 \mathrm{~min}$ of irradiation time, fractions of about $83.3 \pm 5.7$ and $50.7 \pm 4.2 \%$ in cell survival were noted, respectively (Sabbahi et al. 2008b).

After being exposed to visible light in the presence of RB $(20 \mu \mathrm{M})$, an additional photodamaging effect was noted (ANOVA, $p<0.05$ ). The $S$. aureus survival fraction had decreased to $20.6 \pm 1.4 \%$ (with a recorded reduction of $\sim 0.6$ $\log$ units on $S$. aureus viability) after $10 \mathrm{~min}$ of irradiation time $\left(50 \mathrm{~mW} / \mathrm{cm}^{2}\right.$; light fluence of $30 \mathrm{~J} / \mathrm{cm}^{2}$ ) (Table 2).

To investigate whether photo-oxidation of Type I or II are the predominant action mechanisms; D-mannitol, a quencher of hydroxyl radical (Type I) and tryptophan or sodium azide, quenchers of singlet oxygen (Type II) were used (Street et al. 2009). The results, resumed in Table 2, show that under these conditions, sodium azide (10 mM), which is known to react especially with singlet oxygen (Costa et al. 2013) and mainly as a physical quencher of ${ }^{1} \mathrm{O}_{2}$ (Bancirova 2011), failed to show any bacteria protection as the same survival fraction (20\%) for the RB alone was obtained. As shown in Table 2, L-Trp, used as singlet oxygen trapping
Table 2 Photoinactivation of $S$. aureus cultures in PBS $(\mathrm{pH} 7,3)$ treated with $\mathrm{RB}(20 \mu \mathrm{M})$ and artificial visible light $\left(50 \mathrm{~mW} \mathrm{~cm}{ }^{-2}\right)$ in the presence of three antioxidants $(10 \mathrm{mM})$ after 10 and $30 \mathrm{~min}$ of phototreatment at light fluence doses of 30 and $90 \mathrm{~J} \mathrm{~cm}^{-2}$, respectively

\begin{tabular}{|c|c|c|c|}
\hline \multirow[t]{2}{*}{ Medium } & \multicolumn{3}{|c|}{ Viability after $10 \mathrm{~min}$ of phototreatment } \\
\hline & $\mathrm{CFU} \mathrm{ml} \mathrm{m}^{-1}$ & $\begin{array}{l}\text { Survival fraction } \\
(\%)\end{array}$ & $\begin{array}{l}\text { Inactivated bac- } \\
\text { teria }(\%)\end{array}$ \\
\hline Without RB & $4.2 \times 10^{7}$ & $82.3 \pm 5.7$ & $17.6 \pm 5.7$ \\
\hline RB alone & $10.5 \times 10^{6}$ & $20.6 \pm 1.4$ & $79.4 \pm 1.4$ \\
\hline $\mathrm{RB}+\mathrm{N}_{3}^{-\mathrm{a}}$ & $10.2 \times 10^{6}$ & $20.0 \pm 0.7$ & $80.0 \pm 0.7$ \\
\hline $\mathrm{RB}+\operatorname{Trp}^{\mathrm{b}}$ & $5.1 \times 10^{7}$ & $>99 \pm 0.1$ & $<0.1 \pm 0.1$ \\
\hline $\mathrm{RB}+$ mannitol & $5.1 \times 10^{7}$ & $>99 \pm 0.1$ & $<0.1 \pm 0.1$ \\
\hline \multicolumn{4}{|c|}{ Viability after $30 \mathrm{~min}$ of phototreatment } \\
\hline Without RB & $2.6 \times 10^{7}$ & $51.0 \pm 4.2$ & $49.0 \pm 4.2$ \\
\hline RB alone & $4.1 \times 10^{6}$ & $8.0 \pm 0.4$ & $91.9 \pm 0.4$ \\
\hline $\mathrm{RB}+\mathrm{N}_{3}^{-}$ & $1.5 \times 10^{6}$ & $2.9 \pm 0.4$ & $97.0 \pm 0.4$ \\
\hline $\mathrm{RB}+\operatorname{Trp}$ & $2.0 \times 10^{6}$ & $3.9 \pm 1.0$ & $96.1 \pm 1.0$ \\
\hline $\mathrm{RB}+$ mannitol & $5.1 \times 10^{6}$ & $10.0 \pm 0.2$ & $90.0 \pm 0.2$ \\
\hline
\end{tabular}

S. aureus: Staphylococcus aureus, $P B S$ Phosphate buffer solution, $R B$ rose bengal, $\mathrm{NaN}_{3}$ sodium azide

${ }^{\mathrm{a}} \mathrm{N}_{3}^{-}$anion azide reactive, ${ }^{\mathrm{b}} \operatorname{Tr} p$ tryptophan

agent (Street et al. 2009), protected significantly S. aureus against photoactivated RB by $78 \%$ (its survival is more than $99 \% ; 0.69 \log$ units reduction on bacteria photoinactivation rate) after $10 \mathrm{~min}$ of phototreatment (ANOVA, $p<0.05$ ). The same extent of $S$. aureus protection as obtained by LTrp, occurred in the presence of D-mannitol, as an alcoholic sugar which has an antioxidant effect; it reacts especially with hydroxyl free radical (Liang et al. 2008; Al-Omari and Ali 2009). Accordingly, this substance is considered to be a strong free radical scavenger (Sagone et al. 1983; Kamat et al. 2000). Some experiments have shown that it can prevent enzymes inactivation such as glucose-6-phosphate dehydrogenase (G6PD), nitrate-reductase and sulphite oxidase by ionizing radiations (Eichler et al. 1987). D-mannitol can protect supercoiled DNA from hydroxyl radical damage due to ionizing radiation (Peak et al. 1995). The rate of photoprotection powered by L-Trp and D-mannitol was significant (ANOVA, $p<0.05$ ) during the first $10 \mathrm{~min}$ of illumination (Table 2). These results prove that the RB photosensitization reaction, was especially proceeded by the Type I pathway generating predominantly hydroxyl radicals (.OH) and Type II ( ${ }^{1} \mathrm{O}_{2}$ production). For sodium azide as singlet oxygen quencher, there is no bacterial protection than that obtained in the presence of L-Trp which was comparable to that obtained with D-mannitol, used as free radical scavenger. The results obtained for sodium azide and L-Trp with the RB are unexpected since both are considered in the literature, as singlet oxygen quenchers (Tavares et al. 2011). The results obtained show that the selection of L-Trp 
as singlet oxygen quencher can give, depending on the PS, erroneous information about the type of mechanism involved in the photodynamic inactivation process. Thirty minutes after treatment by RB and light, the sensitized $S$. aureus lost more than $90 \%$ of its viability (reduction of $1 \log$ unit). The same rate of killing occurred in the presence of quenchers which failed to show any protection (Table 2). On the other hand, the quenchers that proved their protective ability showed that the killing rate in their presence was reduced to almost the same extent as the protection provided by them. We propose two possible explanations. The first one is that RB molecules, in the absence of culture media (in saline), might be in close contact with the bacteria, ROS produced mainly HO. and ${ }^{1} \mathrm{O}_{2}$, might not be stopped efficiently by quenchers with increasing contact time. Consequently, a high percentage of the bacteria population is killed. Similar explanation was reported by Nitzan et al. (1989) under their own experimental conditions. The second explanation concerns the concentration used of the quenchers. In fact, in all the protection experiments, the amount of the proposed quenchers was 500-fold higher than the amount of the RB added to the culture. According to authors, a plausible explanation can be the use of low quencher concentrations. The choice of the folding between PS and quenchers used was inspired from the work of Nitzan et al. (1989), in all their protection experiments, the amount of the proposed quencher was 70-700-fold higher than the amount of the overall PS added to the culture.

\section{Spectrophotometric study}

The spectrophotometric study has been complimented with the RB photodynamic effect on $S$. aureus in vitro inactivation in saline solution (PBS) with the presence of the Trp antioxidant. This experiment was conducted to reveal the possibility of interactions between the antioxidant and the dye which could be associated with further understanding of the RB mechanisms photodynamic action.

The visible absorption spectra of RB disodium salt with a fixed concentration of $20 \mu \mathrm{M}$ in PBS over $400-700 \mathrm{~nm}$ wavelength range with or without $S$. aureus suspension and L-Trp (10 mM) are summarized in Fig. 2a and b.

The maximum absorption ( $\lambda \max$ ) for the RB in PBS, were observed around 500 and $549 \mathrm{~nm}$ (Fig. 2(1a)). The loose ion pairs exhibit the same spectral shape as does the dianion in dilute aqueous solution (Linden and Neckers 1988). These peaks intensity decreased slightly after $10 \mathrm{~min}$ of visible irradiation (Fig. 2(2a)). Rose bengal spectrum in saline solution in the presence and the absence of $10 \mathrm{mM}$ of L-Trp is reported in Fig. 2(3a), (4a). Before illumination, the peak amplitude at $549 \mathrm{~nm}$ decreased from 2.441 in the absence of L-Trp (Fig. 2(1a)) to 2.046 in its presence (hypochromic effect) (Fig. 2(3a)). This reduction in
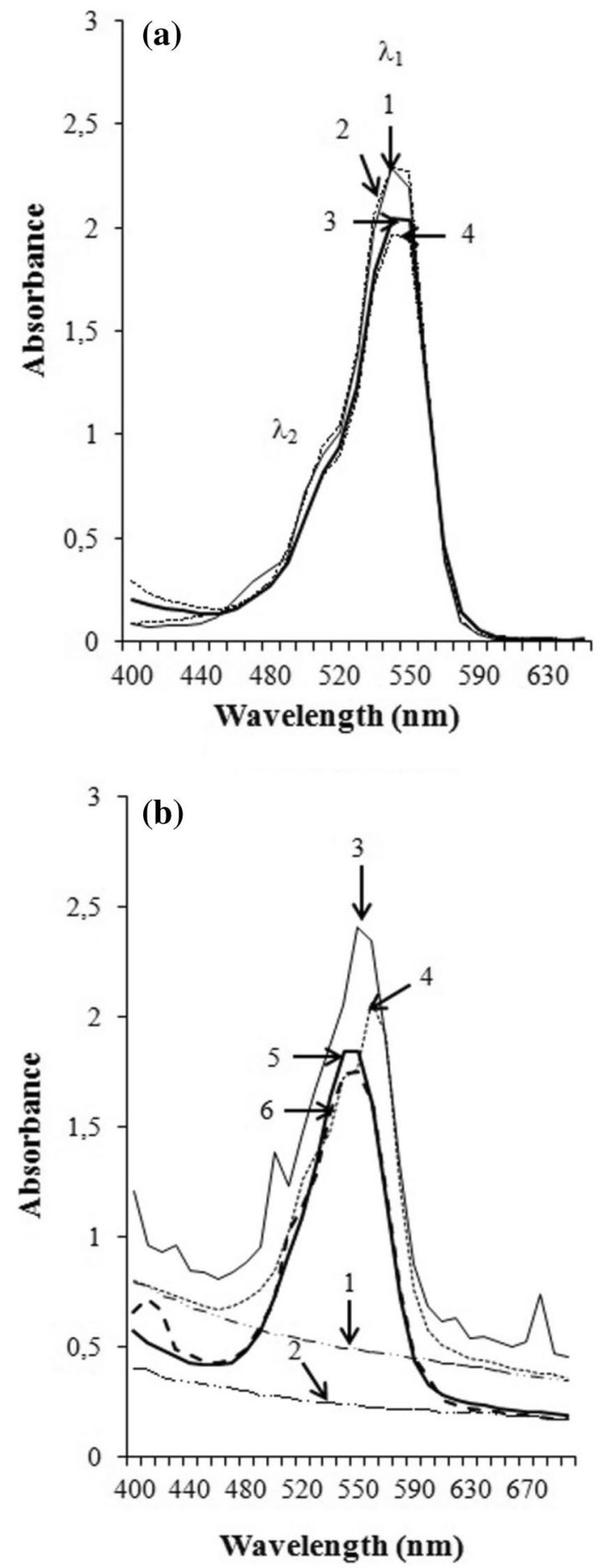

Fig. 2 Effects of $S$. aureus and Trp on the spectral characteristics of RB. Absorbance curves of $\mathrm{RB}$ at the dye concentration of $20 \mu \mathrm{M}$ : a Without bacteria: (1) in PBS protected from light and (2) after $10 \mathrm{~min}$ of visible irradiation time at a light fluence dose of $30 \mathrm{~J} / \mathrm{cm}^{2},(3)$ in the presence of $\operatorname{Trp}(10 \mathrm{mM})$ protected from light and (4) after $10 \mathrm{~min}$ of visible irradiation time. b In the presence of $S$. aureus at a concentration of $5.110^{7}$ $\mathrm{CFU} \mathrm{ml} \mathrm{m}^{-1}$ : (1) absorbance curve of $S$. aureus protected from light in the absence of RB and antioxidants and (2) after $10 \mathrm{~min}$ of visible irradiation time, (3) in the presence of RB in PBS before and (4) after $10 \mathrm{~min}$ of visible irradiation time, (5) in the presence of RB and Trp before and (6) after 10 min of visible irradiation time 
absorbance demonstrates that some fractions of both the dye and aminoacid molecules were actively involved in ground state intermolecular interactions. After $10 \mathrm{~min}$ of visible irradiation, the peak amplitude at $549 \mathrm{~nm}$ diminished (hypochromic effect) slowly reaching 1.964 (Fig. 2(4a)).

Figure $2 \mathrm{~b}$ demonstrates the behaviour of the RB monomer absorbance following bacteria addition $\left(5.1 \times 10^{7} \mathrm{CFU} /\right.$ $\mathrm{mL})$. S. aureus growth controls are representing in the two curves, respectively of Fig. 2(1b), (2b), meaning without the addition of any RB or Trp antioxidant, and respectively in the absence of light and after $10 \mathrm{~min}$ of light exposure. In the presence of $\mathrm{RB}$, the $S$. aureus addition induced a small decrease of its absorbance where the longer wavelength peak shifts $1 \mathrm{~nm}$ to the red region of the spectrum $\left(A_{550 \mathrm{~nm}}=2.40\right)$; commonly called small bathochromic effect. Hence, the RB absorption spectrum in the presence of $S$. aureus suspended in saline solution showed three sharper peaks at 500, 550 and $680 \mathrm{~nm}$ (Fig. 2(3b)). According to specific conditions of Neckers (1989), it can be assumed that the shortest wavelength of this absorption spectrum was due to the contact ion pair, whereas the higher one was a result of the totally dissociated dianion. Under the same condition, after exposure to visible light during $10 \mathrm{~min}$, the shorter wavelength peak amplitude increased and the longer one shifted approximately to $10 \mathrm{~nm}$ toward the red (bathochromic effect $)$ associated to an hyperchromism $\left(A_{560 \mathrm{~nm}}=2.49\right)$ (Fig. 2(4b)). Abuin et al. (2007) and Alarcón et al. (2009) assigned this behaviour to the presence of two species: RB free (band at 548-549 nm) and RB bound to protein (band at 560-562 nm). For Chang et al. (2008), in their proper experimental conditions, argued that the addition of lipid results in the red shift favour the absorption of the species at $\approx 563$ and $\approx 523 \mathrm{~nm}$ probably due to the attachment of the RB to the bacteria. A disappearance of the peak centred at $680 \mathrm{~nm}$ was also observed. Linden and Neckers (1988) reported that the extent of ionisation at C- 6 is function of solvent polarity and concentration. The absorption maxima of the C-2' esters were shifted; however, about $10 \mathrm{~nm}$ to the red in $S$. aureus suspension relative to the disodium salt as that RB can be esterified at C-2' (the carboxylate position) selectively.

The spectra of the RB, in the presence of $S$. aureus with and without L-Trp (10 mM) are compared in Fig. 2(3b-6b). Since the amino acids do not absorb in the visible (Martínez et al. 1993), the species absorbing in the 500 and $549 \mathrm{~nm}$ regions should be free RB. Obviously from the comparison of the two spectra curves, there is some broadening in the spectrum of L-Trp introduced to $S$. aureus suspension in the presence of RB (Fig. 2(5b)). This is showing a disturbance in the RB spectrum in the normally sharp pair of peaks in the $500-550 \mathrm{~nm}$ regions, indicating a possible complex formation of RB with the L-Trp in saline medium. Most evident spectral changes occur with the presence of L-Trp and when they are irradiated in solvent with the possibility of products formation, characteristics of their reaction (Fig. 2(6b)). This could be explained by the fact that when irradiated, L-Trp could interact with RB resulting in products, which absorb at $410 \mathrm{~nm}$ (Fig. 2(6b)). In another way, Inoue et al. (1982) in their experimental conditions reported that RB sensitized photo-oxidation of L-Trp in aqueous environment at $\mathrm{pH}$ between 6 and 7 results mainly in the formation of another product which is the $N$-hydroxyperoxy-hydropyrolle-indole carboxylic acid (HPI). Similar behaviour has been reported lately with hydroperoxides formed on Trp oxidation (Gracanin et al. 2009). In the presence of phosphate buffer, the effect of L-Trp on the absorption spectra of RB was practically similar to that shown in Fig. 2a, and to the RB spectra obtained in aqueous solution (Linden and Neckers 1988), indicating that the salinity of the medium does not appreciably affect the binding, pointing to a minor importance of electrostatic interactions. The factors affecting the interactions between components and L-Trp may include hydrophobic interactions. Further, this could be explained by the fact that when the dye is bound to the amino acid, at low oxygen concentration, trapping by oxygen of the triplet becomes inefficient and type I processes could contribute to the observed photoprocess.

Under the same conditions, Sabbahi et al. (2008b) showed that thanks to the interactions between monocationique methylene blue (MB) and S. aureus, a metachromatic reaction took place between MB and the bacteria, inducing additional dimerization of MB. Then, when Trp was introduced to the medium, the dye molecules would redistribute with a decrease in the bound dye aggregate molecules as witnessed by the dimer peak disappearance. Therefore, the MB monomer species were responsible for photodestruction of S. aureus bacteria.

According to author knowledge, little is known about the effect of xanthenes dyes on bacterial membrane functions. Recently, Kato et al. (2012) showed the amounts of the dye bound to $S$. aureus cells estimated to be $54 \%$ at $1 \mu \mathrm{M}$. This amount was correlated with the potency of dye-induced photoinactivation of bacterial membrane functions. Demidova and Hamblin (2005) showed that the anionic dye RB had no detectable binding to $S$. aureus but was nevertheless highly efficient in mediating PDI killing. Most common, Gram-positive species lack a barrier comparable to the outer Gram-negative-bacteria cell wall. For this reason, Dahl et al. (1988) moved forward that anionic compounds, such as RB, which are excluded from the Gram-negative bacterial cell interior, may penetrate the Gram-positive exterior more readily. This is in agreement with our result referring to the absorption spectrum change (particularly bathochromic effect) when $S$. aureus was irradiated for $10 \mathrm{~min}$ in the presence of RB. In its presence, two distinct behaviours were observed when L-Trp and $\mathrm{NaN}_{3}$ were used as singlet oxygen 
quenchers. In fact, the presence of L-Trp (10 mM) led to a bacterial protection similar to the one observed with D-mannitol; while in the presence of sodium azide, no protection was detected. The high inhibition of the PS activity by LTrp would not only be due to its singlet oxygen quencher ability but also to the interaction between RB and L-Trp as witnessed by spectrophotometric study. Many available literature data have shown that RB was well-known to operate via the Type II photosensitization mechanism (Redmon and Gamlin 1999; Gracanin et al. 2009) which were associated to the environment of the PS, and to the absence of pre-defined parameters for using PDI according to their experimental conditions (Rossoni et al. 2010). This paper represents a report of the mechanisms of RB photodynamic inactivation of $S$. aureus in phosphate buffer solution (PBS). The main objective was to determine which ROS is more effective for $S$. aureus using RB that tend to undergo Type I and/or Type II mechanisms (OH. and ${ }^{1} \mathrm{O}_{2}$, respectively), as the two highly active oxidizing agents involved in photodynamic inactivation or phototherapy (Huang et al. 2012; Wen et al. 2017). The obtained data suggested that the RB photosensitization reaction, was especially proceeded by the Type I pathway (hydroxyl radicals $(\mathrm{OH}$.) quenched by mannitol) and Type II ( ${ }^{1} \mathrm{O}_{2}$ quenched by Trp). Surprisingly, nonquenchable ${ }^{1} \mathrm{O}_{2}$ was detected in the presence of sodium azide $\left(\mathrm{NaN}_{3}\right)$, as a well-known singlet oxygen quencher. In agreement with the results obtained and aforementioned, an explanation of mechanisms of the RB photodynamic action against $S$. aureus is that a possible quenching of the RB excited triplet state $\left({ }^{3} \mathrm{RB}^{*}\right)$ by L-Trp has been proposed, as a concomitant consequence of interaction between ${ }^{3} \mathrm{RB}^{*}$ and L-Trp and it found to give rise to a large absorption change near $410 \mathrm{~nm}$, and may compete with reaction between Trp and singlet oxygen $\left({ }^{1} \mathrm{O}_{2}\right)$ in aqueous solution. Although, the precise nature of this interaction, products generated and their contribution have not been elucidated, it has been reported by Seret and Van de Vorst (1990) that the quenching of triplet excited state of RB $\left({ }^{3} \mathrm{RB}^{*}\right)$ by Trp in aqueous solution, generated semireduced RB as a product obtained through this interaction, but no information about rate constants was given in their research (Criado et al. 1996). Therefore, this interaction between RB and L-Trp would be the cause of reduction of the RB microbial killing not as a reactive product. This explains the lack of correlation between RB photoinactivation efficiency and its interaction capability with Trp shown by our study. In summary, not only the use of singlet oxygen quenchers and of the free radical scavengers as simple approach to determine which pathway(s) is (are) involved in PDI (Nitzan et al. 1989; Song et al. 1999; Huang et al. 2012) but also the spectroscopic study of possible interaction between the PS and some quenchers such as Trp, used in this study, in the presence of bacteria, are important characteristics for determining photochemical mechanisms involved in the photodynamic process. Spectral studies can be a simple and useful screening gate to understand more of the mechanisms action of PSs used for wastewater disinfection.

In addition to the spectrophotometric study, further work will be necessary to confirm some of these hypothetical explanations mentioned above through our experimental observations and to identify the products found. Nevertheless, it can be suggested to use a higher amount of the antioxidant's concentration and to use more antioxidants (singlet oxygen quenchers and free radicals scavengers). We believe that a trial as relatively simple experimental system corresponding to an evaluation in the simultaneous presence of antioxidants at higher concentration than the tested one in the present work to inhibit the action of both active reactive oxygen species, will have the potential to better identify RB reaction mechanisms.

\section{Conclusions}

Our results illustrate that under visible light and in the presence of $20 \mu \mathrm{M} \mathrm{RB}$, a higher killing efficiency for $\mathrm{S}$. aureus during $10 \mathrm{~min}$ of phototreatment was led. The $S$. aureus survival decreases with increasing irradiation time in the presence of PS. The hydroxyl free radicals (Type I mechanism) plays the most important role on the photoinactivation process of the tested bacteria by the dianionic rose bengal. However, a contribution of Type II pathway cannot be discounted, in the presence of the singlet oxygen quencher Tryptophan. Despite the presence of sodium azide found to be selective singlet oxygen quencher, no significant protection was noted for RB after 10 min of phototreatment. From the results obtained, the selection of L-Trp as singlet oxygen quencher, depending on the PS and its environment complimented with the spectrophotometric study can give, supplementary information about the type of mechanism involved in the photoinactivation process.

Therefore, it was of great interests to characterize further the bacterial targets, physicochemical and spectroscopic properties of PSs and finally the number of antioxidants used.

Open Access This article is distributed under the terms of the Creative Commons Attribution 4.0 International License (http://creativeco mmons.org/licenses/by/4.0/), which permits unrestricted use, distribution, and reproduction in any medium, provided you give appropriate credit to the original author(s) and the source, provide a link to the Creative Commons license, and indicate if changes were made. 


\section{References}

Abuin E, Aspée A, Lissi E, León L (2007) Binding of rose bengal to bovine serum albumin. J Chil Chem Soc 52(2):1196-1197. https ://doi.org/10.4067/S0717-97072007000200017

Agnez-Lima LF, Melo JTA, Silva AE, Oliveira AHS, Timoteo ARS, Lima-Bessa KM, Martinez GR, Medeiros MHG, Di Mascio P, Galhardo RS, Menck CFM (2012) DNA damage by singlet oxygen and cellular protective mechanisms. Mutat Res-Rev Mutat 751:15-28. https://doi.org/10.1016/j.mrrev.2011.12.005

Alarcón E, Edwards AM, Aspée A, Borsarelli CD, Lissi EA (2009) Photophysics and photochemistry of rose bengal bound to human serum albumin. Photochem Photobiol Sci 8(7):933-943. https:// doi.org/10.1039/b901056d

Al-Omari S, Ali A (2009) Photodynamic activity of pyropheophorbide methyl ester and pyropheophorbide a in dimethylformamide solution. Gen Physiol Biophys 28(1):70-77. https://doi.org/10.4149/ gpb_2009_01_70

Bancirova M (2011) Sodium azide as a specific quencher of singlet oxygen during chemiluminescent detection by luminol and Cypridina luciferin analogues. Luminescence 26(6):685-688. https://doi.org/10.1002/bio.1296

Calin MA, Parasca SV (2009) Light sources for photodynamic inactivation of bacteria. Lasers Med Sci 24(3):453-460. https://doi. org/10.1007/s10103-008-0588-5

Chang CC, Yang YT, Yang JC, Wu HD, Tsaib T (2008) Absorption and emission spectral shifts of rose Bengal associated with DMPC liposomes. Dyes Pigment 79(2):170-175. https://doi. org/10.1016/j.dyepig.2008.02.003

Chilvers KF, Reed RH, Perry JD (1999) Phototoxicity of rose Bengal in mycological media implications for laboratory practice. Lett Appl Microbiol 28:103-107. https://doi.org/10.104 6/j.1365-2672.1999.00492.x

Costa ACBP, Junior JC, Pereira CA, da Silva Machado AK, Junior MB, Junqueira JC, Jorge AOC (2010) Susceptibility of planktonic cultures of Streptococcus mutans to photodynamic therapy with a light-emitting diode. Braz Oral Res 24(4):413-418. https://doi. org/10.1590/S1806-83242010000400007

Costa L, Faustino MAF, Tomé JPC, Neves MGPMS, Tomé AC, Cavaleiro JAS, Cunha Â, Almeida A (2013) Involvement of Type I and Type II mechanisms on the photoinactivation of non-enveloped DNA and RNA bacteriophages. J Photochem Photobiol B 120:10 16. https://doi.org/10.1016/j.jphotobiol.2013.01.005

Criado S, Bertolotti SG, García NA (1996) Kinetic aspects of the rose bengal-sensitized photo-oxygenation of tryptophan alkyl esters Ground state and photopromoted dye-tryptophan derivative interactions. J Photochem Photobiol B. https://doi.org/10.1016/10111344(95)07274-8

Dahl TA, Midden WR, Neckers DC (1988) Comparison of photodynamic action by rose bengal in Gram-positive and Gram-negative bacteria. Photochem Photobiol 48:607-612. https://doi. org/10.1111/j.1751-1097.1988.tb02870.x

Demidova TN, Hamblin MR (2005) Effect of cell-photosensitizer binding and cell density on microbial photoinactivation. Antimicrob Agents Chemother 49(6):2329-2335. https://doi.org/10.1128/ AAC.49.6.2329-2335.2005

DeRosa MC, Crutchley RJ (2002) Photosensitized singlet oxygen and its applications. Coord Chem Rev 233-234:351-371. https://doi. org/10.1016/S0010-8545(02)00034-6

Eichler DC, Solomonson LP, Barber MJ, McCreery MJ, Ness GC (1987) Radiation inactivation analysis of enzymes. Effect of free radical scavengers on apparent target sizes. J Biol Chem 262(20):9433-9436
Gandin E, Lion Y, van de Vorst A (1983) Quantum yield of singlet oxygen production by xanthene derivatives. Photochem Photobiol 37:271-278. https://doi.org/10.1111/j.1751-1097.1983.tb04472.x

Gollnick K (1978) Mechanisms and kinetics of chemical reactions of singlet oxygen with organic compounds. In: Ranby B, Rabek JF (eds) Singlet oxygen reactions with organic compounds and polymers. Wiley, New York, pp 111-134

Gracanin M, Hawkins CL, Pattison DI, Davies MJ (2009) Singletoxygen-mediated amino acid and protein oxidation: formation of tryptophan peroxides and decomposition products. Free Radic Biol Med 47(1):92-102. https://doi.org/10.1016/j.freeradbio med.2009.04.015

Huang L, Xuan Y, Koide Y, Zhiyentayev T, Tanaka M, Hamblin MR (2012) Type I and Type II mechanisms of antimicrobial photodynamic therapy: an in vitro study on Gram-negative and Grampositive bacteria. Lasers Surg Med 44(6):490-499. https://doi. org/10.1002/lsm.22045

Inoue K, Matsuura T, Saito I (1982) Mechanism of dye-sensitized photo-oxidation of tryptophan. Tryptamine and their derivatives. Singlet oxygen process in competition with Type I process. Bull Chem Soc Jpn 55(9):2959-2964. https://doi.org/10.1246/ bcsj.55.2959

Jemli M, Alouini Z, Sabbahi S, Gueddari M (2002) Destruction of faecal bacteria in wastewater by three photosensitizers. J Environ Monit 4(4):511-516. https://doi.org/10.1039/B204637G

Kamat JP, Boloor KK, Devasagaym TP (2000) Chlorophyllin as an effective antioxidant against membrane damage in vitro and ex vivo. Biochem Biophys Acta 1487(2-3):113-127. https://doi. org/10.1016/S1388-1981(00)00088-3

Kato H, Kamagoe K, Nakanishi Y, Inoue T, Katsu T (2012) Xanthene dyes induce membrane permeabilization of bacteria and erythrocytes by photo in activation. Photochem Photobiol 88(2):423-431. https://doi.org/10.1111/j.1751-1097.2012.01080.x

Liang SX, Zhao LX, Zhang BT, Lin JM (2008) Experimental studies on the chemiluminescence reaction mechanism of carbonate/ bicarbonate and hydrogen peroxide in the presence of cobalt(II). J Phys Chem 112(4):618-623. https://doi.org/10.1021/jp0761822

Linden SM, Neckers DC (1988) Type I and Type II sensitizers based on rose Bengal onium salts. Photochem Photobiol 47:543-550. https ://doi.org/10.1111/j.1751-1097.1988.tb08842.x

Martínez G, Bertolotti SG, Zimerman OE, García NA (1993) A kinetic study on the photodynamic properties of the xanthene dye merbromin (mercurochrome) and its aggregates with amino acids in aqueous solution. J Photochem Photobiol B 17(3):247-255. https ://doi.org/10.1016/1011-1344(93)80022-2

Michaeli A, Feitelson J (1995) Reactivity of singlet oxygen toward large peptides. Photochem Photobiol 61(3):255-260. https://doi. org/10.1111/j.1751-1097.1995.tb03968.x

Michaeli A, Feitelson J (1997) Reactivity of singlet oxygen toward proteins: the effect of structure in basic pancreatic trypsin inhibitor and in ribonuclease A. Photochem Photobiol 65(2):309-315. https://doi.org/10.1111/j.1751-1097.1997.tb08563.x

Moan J, Peng Q (2003) An outline of the hundred-year history of PDT. Anticancer Res 23(5A):3591-3600

Neckers DC (1989) Rose Bengal. J Photochem Photobiol A 47(1):1-29. https://doi.org/10.1016/1010-6030(89)85002-6

Nitzan Y, Shainberg B, Malik Z (1989) The mechanism of photodynamic inactivation of Staphylococcus aureus by deuteroporphyrin. Curr Microbiol 19:265-269

Oliveira PS, Souza SG, Campos GB, da Silva DCC, Sousa DS, Araújo SPF, Ferreira LP, Santos VM, Amorim AT, Santos AM, Timenetsky J, Cruz MP, Yatsuda R, Marques LM (2014) Isolation, pathogenicity and disinfection of Staphylococcus aureus carried by insects in two public hospitals of Vitóriada Conquista, Bahia, Brazil. Braz J Infect Dis 18(2):129-136. https://doi.org/10.1016/j. bjid.2013.06.008 
Paulino TP, Magalhães PP, Thedei G, Tedesco AC, Ciancaglini P (2005) Use of visible light-based photodynamic therapy to bacterial photoinactivation. Biochem Mol Biol Educ 33(1):46-49. https ://doi.org/10.1002/bmb.2005.494033010424

Peak JG, Ito T, Robb FT, Peak MJ (1995) DNA damage produced by exposure of supercoiled plasmid DNA to high-and low LET ionizing radiation effects of hydroxyl radical quenchers. Int J Radiat Biol 67(1):1-6

Redmon RW, Gamlin JN (1999) A compilation of singlet oxygen yields from biologically relevant molecules. Photochem Photobiol 70:391-475. https://doi.org/10.1111/j.1751-1097.1999.tb08240.x

Rossoni RD, Junqueira JC, Santos EL, Costa AC, Jorge AO (2010) Comparison of the efficacy of rose Bengal and erythrosine in photodynamic therapy against Enterobacteriaceae. Lasers Med Sci 25(4):581-586. https://doi.org/10.1007/s10103-010-0765-1

Sabbahi S, Alouini Z, Jemli M, Ben Ayed L, Boudabbous A, Lahmar S (2008a) Destruction photodynamique des œufs de Taeniidés et de Toxocara sp dans l'eau. Cahiers de l'ASEES 13(1):31-41. https:// doi.org/10.1051/asees/20081301031

Sabbahi S, Alouini Z, Jemli M, Boudabbous A (2008b) The role of reactive oxygen species in Staphylococcus aureus photoinactivation by methylene blue. Water Sci Technol 58(5):1047-1054. https ://doi.org/10.2166/wst.2008.471

Sabbahi S, Ben Ayed L, Boudabbous A (2013) Cationic, anionic and neutral dyes: effects of photosensitizing properties and experimental conditions on the photodynamic inactivation of pathogenic bacteria. J Water Health 11(4):590-599. https://doi.org/10.2166/ wh.2013.219

Sagone AL, Democko C, Clark L, Kartha M (1983) Determination of hydroxyl radical production in aqueous solutions irradiated to clinically significant doses. J Lab Clin Med 101(2):196-204

Seret A, Van de Vorst A (1990) Solubility properties of Eosin and rose Bengal triplet state in sodium dodecyl sulphate micellar solutions. J Phys Chem 94(13):5293-5299. https://doi.org/10.1021/ j100376a025

Shevchuk IN, Chekulayev VA, Chekulayeva LV (2002) The role of lipid peroxidation and protein degradation in the photodestruction of Ehrlich ascites carcinoma cells sensitized by hematoporphyrin derivative. Exp Oncol 24(3):216-224

Shrestha A, Hamblin MR, Kishena A (2012) Characterization of a conjugate between rose Bengal and Chitosan for targeted antibiofilm and tissue stabilization effects as a potential treatment of infected dentin. Antimicrob Agents Chemother 56(9):4876-4884. https:// doi.org/10.1128/AAC.00810-12

Song YZ, An J, Jiang L (1999) ESR evidence of the photogeneration of free radicals (GDHB*-, O2*-) and singlet oxygen ((1)O2) by 15-deacetyl-13-glycine-substitued hypocrellin B. Biochim Biophys Acta 1472(1-2):307-313. https://doi.org/10.1016/S0304 $-4165(99) 00137-3$

Street CN, Gibbs A, Pedigo L, Andersen D, Loebel NG (2009) In vitro photodynamic eradication of Pseudomonas aeruginosa in planktonic and biofilm culture. Photochem Photobiol 85(1):137-143. https://doi.org/10.1111/j.1751-1097.2008.00407.x

Taniellian C, Mechin R, Seghrouchni R, Schweitzer C (2000) Mechanistic and kinetic aspects of photosensitization in the presence of oxygen. Photochem Photobiol 71(1):12-19. https://doi. org/10.1562/0031-8655(2000)0710012MAKAOP2.0.CO2

Tavares A, Dias SRS, Carvalho CMB, Faustino MAF, Tomé JPC, Neves MGPMS, Tomé AC, Cavaleiro JA, Cunha A, Gomes NC, Alves E, Almeida A (2011) Mechanisms of photodynamic inactivation of a Gram-negative recombinant bioluminescent bacterium by cationic porphyrins. Photochem Photobiol Sci 10(10):16591669. https://doi.org/10.1039/c1pp05097d

Thompson JM, du Gündoğ A, Stratton HM, Katouli M (2013) Antibiotic resistant Staphylococcus aureus in hospital wastewaters and sewage treatment plants with special reference to methicillin-resistant Staphylococcus aureus (MRSA). J Appl Microbiol 114(1):44-54. https://doi.org/10.1111/jam.12037

Wen X, Zhang X, Szewczyk G, El-Hussein A, Huang YY, Sarna T, Hamblin MR (2017) Potassium iodide potentiates antimicrobial photodynamic inactivation mediated by rose Bengal in vitro and in vivo studies. Antimicrob Agents Chemother 61(7):1-15. https ://doi.org/10.1128/AAC.00467-17

Xu D, Neckers DC (1987) Aggregation of rose Bengal molecules in solution. J Photochem Photobiol A 40(2-3):361-370. https://doi. org/10.1016/1010-6030(87)85013-X

Publisher's Note Springer Nature remains neutral with regard to jurisdictional claims in published maps and institutional affiliations. 